Artigos

Volume 10 - $2020 \mid$ n. 1

\title{
A Desvalorização da Remuneração Docente na Disputa pelo Fundo Público Municipal: o caso de Curitiba-PR
}

\author{
Marcus Quintanilha da Silva \\ Universidade Federal do Paraná (UFPR), Curitiba/PR - Brasil
}

\section{Resumo}

Este artigo tem por objetivo analisar as ações de desvalorização dos servidores municipais de Curitiba-PR, particularizando a remuneração docente, com delimitação cronológica de 2016 a abril de 2018. Em um contexto de disputa pelo fundo público municipal, a demanda atual por valorização da remuneração docente e utilizando a Lei de Responsabilidade Fiscal (LRF) como parâmetro, foram analisadas as despesas por função, a dívida pública municipal, as despesas totais com pessoal e suas implicações ao objeto do trabalho. Os resultados evidenciaram que os processos políticos de desvalorização dos servidores do município não se baseiam no cumprimento da LRF, pois, já estava sob controle. Os indícios conduzem para decisões políticas de alocação do fundo público que não compreendem a remuneração do servidor público como investimento, particularmente dos profissionais da educação.

Palavras-chave: Fundo Público. Educação. Financiamento da Educação. Remuneração Docente. Lei de Responsabilidade Fiscal.

\section{The Unappreciation of Teacher Remuneration in the Fight for the Municipal Public Fund: the case of Curitiba-PR}

\begin{abstract}
This article aims to analyze the actions of unappreciation of Curitiba (state of Paraná, Brazil) municipal workers, with a focus on the remuneration between 2016 and April 2018. In a context of fight for the municipal public fund, the current demand for enhancement of teacher remuneration, and using the Fiscal Accountability Law (FAL) as a parameter, it was analyzed the expenditure by position, the municipal government debt, the total expenditure on personnel and its implications to the object of the work. The results showed that the political unappreciation processes of the municipality are not based on the FAL, as it was under control. The evidence leads to political decisions of public fund allocation that do not comprise the remuneration of the public worker as an investment, particularly those who are education providers.
\end{abstract}

Keywords: Public Fund. Education. Education Funding. Teacher Remuneration. Fiscal Accountability Law. 
A Desvalorização da Remuneração Docente na Disputa pelo Fundo Público Municipal

\section{Introdução}

Em um contexto nacional de ações que visam a redução das despesas primárias, congelamento dos investimentos em políticas sociais, perda de direitos e arrocho salarial da classe trabalhadora, particularmente com a Emenda Constitucional n. 95 (BRASIL, 2016), abre-se espaço aos municípios para legitimar, no plano local, políticas análogas, em que segmentos de minoria quantitativa, como banqueiros, grandes empresas e outros atores que disputam o fundo público com as políticas sociais, possam ter vantagem nas decisões locais de alocação do recurso, comprometendo o financiamento da educação e a remuneração dos profissionais do magistério.

Nesse sentido, esse artigo tem por objetivo analisar as ações de desvalorização dos servidores públicos municipais de Curitiba - PR no período entre o final do exercício financeiro de 2016 e abril de 2018, particularizando o caso da remuneração dos profissionais da educação, e, consequentemente, dos docentes. Este trabalho situou essas ações em um contexto de disputa política pelo fundo público no plano municipal, na decisão ausente de neutralidade na alocação do recurso, a demanda atual por valorização do professor pela via da remuneração e a análise do caso da capital paranaense como um exemplo atual de luta pela profissionalização docente.

$\mathrm{Na}$ análise das informações, a utilização de dados quantitativos permeou uma abordagem qualitativa com base nos preceitos da lei complementar n. 101/2000 (BRASIL, 2000), a Lei de Responsabilidade Fiscal (LRF), comumente utilizada em discursos políticos como legitimadora de políticas de austeridade. Para tanto, foram trabalhados os dados sobre despesas por função do portal da transparência de Curitiba, dívida pública municipal e despesas com pessoal, provenientes dos Relatórios de Gestão Fiscal (RGF) entregues ao Tribunal de Contas do Estado do Paraná e a particularidade da remuneração dos profissionais da educação, com informações do Sistema de Informações sobre Orçamentos Públicos em Educação (SIOPE).

Os resultados evidenciaram que, no caso de Curitiba, tanto a dívida pública como as despesas totais com pessoal estavam controladas ao término do exercício financeiro da gestão 2013-2016. Entretanto, os efeitos das políticas de austeridade da atual gestão 20172020, como o congelamento da remuneração dos servidores públicos, reduziram a dívida consolidada pela disponibilidade em caixa e diminuíram o impacto percentual da despesa total com pessoal em relação à receita corrente líquida. Além disso, observou-se na análise de despesas por função novas prioridades à gestão atual, como o aumento substancial em encargos especiais, que incluem os serviços da dívida pública, saneamento e comunicação social, em detrimento às diminuições em educação e saúde, impactantes financeiramente pelo dispositivo constitucional de vinculação de receitas. Buscando compreender a decisão da alocação do recurso como essencialmente política, o panorama de contexto a seguir discute as possibilidades na disputa pelo fundo público municipal.

\section{A Decisão Política da Alocação do Recurso em um Contexto de Disputa pelo Fundo Público Municipal}

Administrar um ente federado não é análogo à administração dos recursos familiares. Todavia, essa analogia é comumente utilizada por boa parte dos gestores municipais para 
A Desvalorização da Remuneração Docente na Disputa pelo Fundo Público Municipal

legitimar as políticas de austeridade que tanto afetam a qualidade do direito à educação. Nesse sentido, uma das prerrogativas do grupo político a frente de uma gestão municipal é a decisão política da alocação do recurso, como característica fundamental do Estado Moderno. $\mathrm{Na}$ compreensão desse processo político interno no município, duas premissas são fundamentais para seu entendimento: a condição de "Estado" dos municípios brasileiros e suas competências constitucionais.

Pela forte aproximação da ordenação jurídica brasileira entre a organização do Estado e o federalismo de cooperação, compreender o município como um espaço de relativa autonomia nos processos decisórios de alocação do recurso exige sua compreensão como um ente dotado de estatalidade. Define-se o termo como "[...] a condição que certa coletividade possui em se autodeterminar, mediante o poder político (coercitivo) de instituir uma ordem jurídica vinculante de uma população situada em um território delimitado" (QUINTILIANO, 2012, p. 92), em que "[...] seu condicionamento ou limitação pelo poder soberano não Ihe retira esse caráter, pois, dentro de tais limites, conserva o poder autônomo o potencial de decidir imperativamente na órbita de sua ordem jurídica" (QUINTILIANO, 2012, p. 85). Portanto, a característica básica é ter um determinado poder de decisão em um limite territorial. As principais características da condição de "Estado" de um ente subnacional são: a) povo; b) território; c) a criação de uma ordem jurídica; d) a legitimação do poder, e; e) uma receita independente.

Povo e território são características básicas dos municípios. A criação de uma ordem jurídica e a legitimação do poder são promovidas pela atual Constituição nos seguintes aspectos: o reconhecimento do município como um ente federado, a prerrogativa de criação de uma lei orgânica municipal, uma espécie de Constituição Municipal, em consonância com as Constituições Estadual e Federal (SOUZA; FARIA, 2004), a designação de competências comuns e exclusivas aos municípios e o próprio reconhecimento dos mesmos como entes federados, que thes dão poder para decidir de que forma irão cumprir com suas responsabilidades, e são previstas pela atual Carta Magna Brasileira (BRASIL, 1988).

Todavia, tais elementos citados não efetivam a condição de estatalidade do município se não houver uma receita independente e certa autonomia para a alocação do recurso. Nesse sentido, o poder de tributar sobre patrimônio, serviços de qualquer natureza e transmissão de bens intervivos, os repasses constitucionais e voluntários da União e os estados e a autonomia federativa, definida como "[...] o poder político coercitivo constituído de criar uma ordem jurídica, constituindo as competências mínimas necessárias para a autodeterminação da sociedade por ela regida, no exercício das quais atua o estado" (QUINTILIANO, 2012, p. 107), bem como a competência financeira e governamental para tomar decisões acerca da alocação do fundo público local, possibilitam, mesmo com os limites de políticas de coordenação federativa da União e receita orçamentária, estabelecer no município um espaço de decisão política na forma que ofertará os serviços públicos.

Portanto, o primeiro contexto apresenta o município como um lugar onde há uma relativa autonomia na decisão da alocação do fundo. Além disso, pelo seu papel estrutural ao capitalismo, o fundo público é um elemento em constante disputa e caracterizando a essa decisão como essencialmente política. Passa-se a entender esse segundo contexto.

Define-se fundo público municipal como a soma de recursos arrecadados pela cobrança de tributos do ente federado de forma direta ou indireta, envolvendo tributações dos 
A Desvalorização da Remuneração Docente na Disputa pelo Fundo Público Municipal

trabalhadores contribuintes ou dos detentores do grande capital, somados aos repasses constitucionais e voluntários dos estados e a União. Em um contexto da política nacional e internacional, a condição estrutural que o fundo público atingiu no desenvolvimento do capitalismo é um fenômeno moderno, potencializado no período posterior à Segunda Guerra Mundial (OLIVEIRA, 1998; POCHMANN, 2004).

Nesse contexto, o Estado passou a intervir, pela via fundo público, nas políticas sociais (OLIVEIRA, 1998), oferecendo melhores condições de vida e seguridade social à população, mas, sendo tensionado de outro lado, através de um espectro de discurso de crise por excesso de gastos do Estado, "[...] sob o comando das políticas neoliberais [...] a liberalização financeira com o enfraquecimento do Estado e da proteção social, sob o efeito dos juros do serviço da dívida" (SALVADOR, 2012, p. 5). Ou seja, nessa perspectiva, a condição estrutural do fundo público implica que:

[...] o fundo público agora é um ex-ante das condições de reprodução de cada capital particular e das condições de vida, em lugar de seu caráter ex-post, típico do capitalismo concorrente. Ele é a referência pressuposta principal, que no jargão de hoje sinaliza as possibilidades de reprodução (OLIVEIRA, 1998, p. 21).

Nesse sentido, a alocação do fundo se encontra em meio a uma disputa, em que o orçamento público aparece menos como uma previsão de gastos e mais como um símbolo e um espaço de luta política (SALVADOR, 2012). Alguns prováveis destinos de uma parcela dessa podem consistir

i. Como fonte importante para a realização do investimento capitalista. No capitalismo contemporâneo, o fundo público comparece por meio de subsídios, de desonerações tributárias, por incentivos fiscais, por redução da base tributária da renda do capital como base de financiamento integral ou parcial dos meios de produção, que viabilizam a reprodução do capital. ii. Como fonte que viabiliza a reprodução da força de trabalho, por meio de salários indiretos, reduzindo o custo do capitalista na sua aquisição. iii. Por meio das funções indiretas do Estado, que no capitalismo atual garante vultosos recursos do orçamento para investimentos em meios de transporte e infraestrutura, nos gastos com investigação e pesquisa, além dos subsídios e renúncias fiscais para as empresas. iv. No capitalismo contemporâneo, o fundo público é responsável por uma transferência de recursos sob a forma de juros e amortização da dívida pública para o capital financeiro, em especial para as classes dos rentistas (SALVADOR, 2012, p. 6-7).

Portanto, o fundo público se caracteriza por um objeto em disputa, e "[...] estrutural ao capitalismo contemporâneo, e, até prova em contrário, insubstituível" (OLIVEIRA, 1998, p. 21). O caso brasileiro, Salvador (2010, p. 617) discorre que:

O fundo público no nosso país historicamente favoreceu a acumulação de capital e apresenta características regressivas, tanto no lado do financiamento tributário, quanto na destinação dos recursos. Em uma única frase é possível definir as características do orçamento público no Brasil: financiado pelos mais pobres e trabalhadores e apropriados pelos ricos.

Além do perfil tributário do país, sem tributos sobre grandes fortunas, ausência de progressividade significativa sobre patrimônio e renda, concentrada no consumo, a uma alocação do recurso público bastante significativa para os juros e amortização da dívida pública. No caso municipal, o contexto da dívida é mais controlado. Em pesquisa aos dados da Secretaria do Tesouro Nacional em abril de 2018 (BRASIL, 2018a), nas informações de 
A Desvalorização da Remuneração Docente na Disputa pelo Fundo Público Municipal

1938 municípios, apenas 24 tinham um descontrole da dívida pública que excedia os limites da Lei de Responsabilidade Fiscal. Todavia, em um contexto onde a financeirização da riqueza, processo de geração de riqueza sem o envolvimento com a produção de mercadorias disputa o fundo público, priorizar a amortização de dívidas controladas também pode ser um destino na decisão política da alocação do recurso.

Compreende-se a decisão da alocação de recurso como um ato ausente de neutralidade (BRETTAS, 2012), e sim norteado por posições políticas contextualizadas por um fenômeno da modernidade: a disputa política pelo fundo público. Alocar o recurso implica em estabelecer uma ordenação de valores, ou, em outras palavras, prioridades (POGGI, 1981), que envolvem posicionamentos do grupo político gestor do ente federado que não privilegiam necessariamente a população de maior vulnerabilidade social. A ação política é sempre no atendimento de uma demanda privada, no sentido que a universalidade de seus atos não implica em uma alocação de recursos que beneficie a todos (FERRAZ, 2011; OLIVEIRA, 1998). Nesse sentido, pensar nas ações do município é compreender que uma demanda nunca é a mesma para toda a população, mas sim para um grupo específico, prioritário na ordenação de valores norteada pelo posicionamento político do Poder Público municipal.

A necessidade de alocação de recursos envolve um processo político interno que, para este tema, dois pontos são fundamentais: a pluralidade de focos e as metas irrestritas (POGGI, 1981; FERRAZ, 2011). A primeira é compreendida como o acesso a diversos pontos de pauta no processo decisório de movimentação de recursos, que, apesar de nem sempre serem provenientes dos mesmos interesses de grupos sociais e políticos, e até mesmo conflitantes entre os Poderes, carecem de atenção por parte do Poder Público. Por metas irrestritas, Ferraz (2011, p. 9) descreve que "[...] o exercício do poder se orienta para alvos cada vez mais abstratos, como o bem-estar geral de um povo ou a felicidade do indivíduo". Nesse sentido, metas e objetivos precisam ser revistos frequentemente, visando o respeito às regras acordadas e o equilíbrio entre as demandas, reforçando a necessidade de compreensão da ordenação de valores do grupo político a frente de uma gestão e a tensão social em busca do atendimento de sua demanda.

Nesse cenário, a perspectiva deste como uma arena de disputa (POULANTZAS, 1985) é condizente com a temática na qual este texto problematiza, haja vista que, na alocação de recursos, há evidência que, nesse processo político de alocação dos recursos, o fundo público se apresenta como um objeto de valor em disputa.

Portanto, esse contexto indica algumas questões importantes nesse trabalho. A decisão da alocação do recurso é sempre política, em meio a uma disputa pelo fundo público que, pelas características do ente federativo municipal, também ocorrem nesse âmbito. Situando a remuneração docente nesse contexto, busca-se a seguir a construção de uma breve retrospectiva que caracterize a luta pela valorização do professor público como histórica e ainda atual, particularmente em contextos políticos onde a referida valorização não está na prioridade da ordenação de valores do Poder Público. 
A Desvalorização da Remuneração Docente na Disputa pelo Fundo Público Municipal

\section{Profissionalização Docente: avanços e retrocessos na valorização da remuneração docente e a atualidade no caso de Curitiba-PR}

A profissionalização docente é entendida como um processo histórico em que a ocupação de professor passou por uma transformação que a configurasse como uma profissão. Nesse sentido, essa seção retomou esse processo através do histórico da valorização dos professores pela via da remuneração, reconhecida como condição importante, mas não única, de valorizar essa classe trabalhadora (GROCHOSKA, 2015).

Por profissionalização, a perspectiva deste trabalho entende como "[...] o ato de buscar transformar algo que se faz de maneira amadora" (OLIVEIRA, 2010, p. 19). Ou seja, nessa visão, o amadorismo da profissão docente buscou dar lugar a uma profissionalização que vem contribuindo para que o pedagógico escolar se torne cada vez mais especializado, seja pela definição de tipos de formação, carreiras, remuneração, entre outras.

A história dos professores dialoga com a evolução (ou não) de sua profissionalização, em que, aspectos como a ampliação da demanda educacional, o Estado como responsável pela oferta e, consequentemente, a necessidade de maior quantidade de docentes foram preponderantes nesse histórico. A perspectiva socio-histórica de Vicentini e Lugli (2009) auxilia no entendimento de que a profissão docente no Brasil passou a ter maior reconhecimento como tal na medida em que ela se profissionalizava, passando por questões como os tipos de vínculo, a oferta em prédios escolares, a remuneração condizente para que a dedicação integral à profissão, entre outras, que perpassam pela construção de um estatuto sócio profissional.

Todavia, alguns fatores são fundamentais na construção do estatuto supracitado. $O$ primeiro é o modelo de federalismo brasileiro. A ampliação da autonomia das províncias e, consequentemente, do poder local, em ofertar a educação primária e selecionar seu funcionalismo público, teve como consequência para o magistério a indicação política de cargos, e não critérios técnicos definidos para a contratação. Além disso, a diferenciação de potencial de investimento e os posicionamentos políticos acerca da educação das massas implicaram em diferentes ritmos de ampliação da oferta e profissionalização docente.

Outro aspecto na busca pela profissionalização é a superação da profissão docente de um viés sacerdotal e de recompensa simbólica para a reivindicação de uma recompensa financeira (OLIVEIRA, 2010; VICENTINI; LUGLI, 2009). Tratou-se, sobretudo, da tensão profissionalização x proletarização, em que, em detrimento ao primeiro termo, durante a década de 1950, a proletarização, "[...] sinônimo do processo de empobrecimento" (VICENTINI; LUGLI, 2009, p. 187), com maior vulto no decênio seguinte, passou a ser ampliada com o crescimento da demanda educacional e a quantidade de docentes, resultando em um movimento de precarização do trabalho docente, em particular nos tipos de contrato, remuneração, formação inicial e visão social da docência. A oposição de trabalho artesanal e profissional, na década de 1960 constataram-se "[...] ameaças de proletarização do magistério primário, com base na deterioração do seu nível de renda e na insatisfação dos professores com o próprio status social" (VICENTINI; LUGLI, 2009, p. 186).

As demandas dos profissionais do magistério culminaram em outras formas de manifestação, desenvolvidas em correlação com o associativismo e sindicalismo docente. Anteriormente a meados da década de 1960 e às grandes manifestações da década posterior, 
A Desvalorização da Remuneração Docente na Disputa pelo Fundo Público Municipal

os movimentos se pautavam na importância da profissão, particularmente no Dia do Professor. Com um sindicalismo mais combativo e reivindicatório por melhores condições de trabalho, os movimentos passaram a ampliar a resistência à proletarização dos professores e transitar a ocupação docente para o status de profissão.

Todavia, foi na década de 1970, auge da ditadura militar, em que houve um grande retrocesso. Apesar da ampliação de atendimento, a partir de 1971 com a Lei n. 5.692 (BRASIL, 1971), e da escolarização obrigatória para o $1^{\circ} \mathrm{grau}$, não houve planejamento e isso incorreu aos entes federados uma intensa busca de professores e prédios escolares que atendessem a essa demanda. A caracterização desse momento consistiu em:

A combinação entre crescimento quantitativo, formação acelerada e arrocho salarial deteriorou ainda mais as condições de vida e de trabalho do professorado nacional do ensino básico, tanto é que o fenômeno social das greves, entre as décadas de 1970 e 1980, teve como base objetiva de manifestação a própria existência material dos professores públicos estaduais de 1o e 20 graus (FERREIRA JÚNIOR; BITTAR, 2006, p. 1166).

O processo de proletarização no seu auge, final da década de 1970, implicou em "[...] uma crise de identidade social do professorado do ensino básico" (FERREIRA JÚNIOR; BITTAR, 2006, p. 1166-1167), já que, o constructo social da profissão reduziu a importância do fazer pedagógico por um profissional especialista e ampliou essa atividade profissional a profissionais liberais.

Desse histórico, implica que as grandes greves, em particular em 1978, 1979 e nos anos 1980 , tiveram no conjunto das políticas educacionais, desde o final da década de 1960 e início da década de 1970 o seu grande fomento. Uma formação incipiente e breve de professores, aliada à expansão desordenada, formas de contratação precárias e a política de arrocho salarial, dentre outros fatores, ainda mantém suas marcas na precarização das condições de trabalho docente, e, particularmente, na remuneração do professor.

Questiona-se a profissionalização como elemento suficiente para que, atualmente, a docência seja uma profissão. Ao discutir a sociologia das profissões, Barbosa (1993) aborda a ideia da profissão como um trabalho específico realizado por detentores de um determinado conhecimento, envolvendo questões como autonomia, formação específica, salário, homogeneidade interna, entre outros. A classe docente não é homogênea, pois, a divisão das responsabilidades educacionais e a diferenciação da valorização dos profissionais das etapas da educação básica e a educação superior, bem como de remuneração entre os entes federados construíram um cenário de diversas carreiras e condições de trabalho, atualmente agravados pela possibilidade de cidadãos com "[...] notório saber reconhecido pelos respectivos sistemas de ensino, para ministrar conteúdos de áreas afins à sua formação ou experiência profissional, atestados por titulação específica ou prática de ensino" (BRASIL, 2017) poderem atuar como docentes no ensino médio, por exemplo.

A demanda por uma remuneração docente que valorize a profissão é atual. O caso recente de Curitiba - PR, uma capital rica e com uma dívida pública sob controle é um exemplo que auxilia no entendimento da continuidade da luta pela valorização profissional. Não é ao acaso que, em determinados momentos históricos, como abordado anteriormente, há um retrocesso na profissionalização docente e em sua remuneração. 
A Desvalorização da Remuneração Docente na Disputa pelo Fundo Público Municipal

O recente percurso político no município de Curitiba - PR culminou em ações que afetaram diretamente a desvalorização dos professores municipais. Primeiramente, o novo plano de carreira, regulado pela Lei Ordinária n. 14.544/2014 (CURITIBA, 2014), foi aprovado pela gestão 2013-2016, com implantação regulamentada através do Decreto n. 387 de 17 de abril de 2015 (CURITIBA, 2015), não foi efetivado, pois, ao final do mandato, o Prefeito não finalizou o enquadramento, deixando milhares de profissionais fora do plano.

Com a assunção da atual administração, as ações de desvalorização foram mais além. A lei municipal n. 15.043 de 28 de junho de 2017 (CURITIBA, 2017) congelou os planos de carreira de todos os servidores, inclusive dos profissionais do magistério que não foram enquadrados pelo novo plano, ainda regulados pela lei n. 10.090/2001 (CURITIBA, 2001), além de, através de outro conjunto de leis, aumentar os descontos percentuais da Previdência e do Instituto Curitiba Saúde. Com intuito de ampliar a austeridade municipal, também mudou a data base dos servidores, sem nenhum diálogo efetivo com a categoria. Apesar da mudança na data base ter como objetivo cumprir com ao menos a reposição da inflação do ano anterior, esta não aconteceu. Ou seja, o cenário, até abril de 2018, não foi somente de congelamento de remuneração, mas de aumento de descontos, e, consequentemente, diminuição do salário líquido.

Os discursos em diversos meios midiáticos (ANÍBAL, 2017) do Prefeito da atual gestão 2017-2020 foram com intuito de controlar os gastos municipais, sempre com o argumento de necessidade do estabelecimento de um regime fiscal prudente ${ }^{1}$. Todavia, os municípios brasileiros já são submetidos à legislação nacional de controle de finanças e gasto com pessoal desde o início da década passada: a lei de responsabilidade fiscal.

Nesse sentido, a seção seguinte busca, através dos preceitos da lei de controle de gasto de pessoal e de dívida pública municipal, compreender como as ações da atual gestão no contexto de disputa pelo fundo público estão se materializando na execução orçamentária, construindo um paralelo com a análise da remuneração dos servidores municipais e, consequentemente, na remuneração docente.

\section{Análise da Dinâmica do Fundo Público no Município de Curitiba entre 2016 e Abril de 2018: considerações sobre o cumprimento da lei de responsabilidade fiscal}

Considerando o contexto de disputa pelo fundo público, a desvalorização da remuneração docente e a investigação de prováveis motivos na ordenação de prioridades do município na alocação da arrecadação municipal, optou-se por fazer uma análise desse movimento com base na lei de responsabilidade fiscal, particularmente por ela servir constantemente como argumento de base no discurso político de legitimação de políticas de austeridade, não sendo diferente no município de Curitiba.

A Lei Complementar n. 101/2000 (BRASIL, 2000), conhecida como a Lei de Responsabilidade Fiscal, uma política de coordenação federativa com vistas a induzir o controle das contas públicas nos entes da federação brasileira, é analisada, para este

\footnotetext{
Alinhamento com a política de ajuste fiscal do Governo Federal no portal da transparência do município. Disponível em: <http://www.curitiba.pr.gov.br/noticias/greca-mostra-resultados-e-reforca-a-meirellescompromisso-com-responsabilidade-fiscal/45098>.
} 
A Desvalorização da Remuneração Docente na Disputa pelo Fundo Público Municipal

trabalho, em duas vertentes. Na primeira, buscou-se a análise na relação de receita corrente líquida, definida no inciso IV do art. $2^{\circ}$ da referida Lei como "[...] o somatório das receitas tributárias, de contribuições, patrimoniais, industriais, agropecuárias, de serviços, transferências correntes e outras receitas também correntes" (BRASIL, 2000, art. 2), deduzidos, no caso dos municípios, da contribuição dos servidores para o custeio do seu sistema de previdência e assistência social e as receitas provenientes da compensação financeira, com as despesas com pessoal, definidas como:

[...] despesa total com pessoal: o somatório dos gastos do ente da Federação com os ativos, os inativos e os pensionistas, relativos a mandatos eletivos, cargos, funções ou empregos, civis, militares e de membros de Poder, com quaisquer espécies remuneratórias, tais como vencimentos e vantagens, fixas e variáveis, subsídios, proventos da aposentadoria, reformas e pensões, inclusive adicionais, gratificações, horas extras e vantagens pessoais de qualquer natureza, bem como encargos sociais e contribuições recolhidas pelo ente às entidades de previdência (BRASIL, 2000, s/p).

Nessas despesas, a lei estabeleceu um limite na execução orçamentária para os municípios de $60 \%$, sendo este distribuído entre $54 \%$ para o Poder Executivo e $6 \%$ para o Legislativo, incluindo o Tribunal de Contas do Município, quando houver. Portanto, para efeitos de cumprimento da legalidade, um município não pode gastar mais de $54 \%$ de sua receita corrente líquida em despesas com pessoal. É estabelecida uma série de sanções da União para municípios e ações da gestão municipal em caso de descumprimento nesse controle de despesas, entre elas o não reajuste salarial e enquadramentos e progressões em planos de carreira. Nesse sentido, este trabalho abrange como objeto de investigação se, nos termos da LRF, este congelamento se justifica, que, no caso da revisão geral anual da remuneração dos servidores, consta no discurso político e na lei n. 15.043/2017 no seu art. $1^{\circ}$ (CURITIBA, 2017).

Em segunda análise, buscou-se compreender o controle da dívida municipal e como essa se envolveu no contexto de alocação do fundo público desde o final da gestão 20132016 até abril de 2018. No dispositivo da LRF, se estabeleceu aos municípios, a partir de sua implantação, um prazo de quinze anos para que o controle da dívida pública se adequasse aos parâmetros definidos pelo Senado Federal na Resolução n. 40 de 2001 (BRASIL, 2001). Nessa normativa, entende-se como dívida pública consolidada:

\footnotetext{
[...] montante total, apurado sem duplicidade, das obrigações financeiras, inclusive as decorrentes de emissão de títulos, do Estado, do Distrito Federal ou do Município, assumidas em virtude de leis, contratos, convênios ou tratados e da realização de operações de crédito para amortização em prazo superior a 12 (doze) meses, dos precatórios judiciais emitidos a partir de 5 de maio de 2000 e não pagos durante a execução do orçamento em que houverem sido incluídos, e das operações de crédito, que, embora de prazo inferior a 12 (doze) meses, tenham constado como receitas no orçamento (BRASIL, 2001, s/p).
}

O parâmetro de referência estabeleceu para os municípios brasileiros que o controle da dívida não poderia exceder a razão entre a Dívida Consolidada Líquida (DCL), definida como "[...] dívida pública consolidada, deduzidas as disponibilidades de caixa, as aplicações financeiras e os demais haveres financeiros" (BRASIL, 2001, s/p) e a Receita Corrente Líquida $(R C L)$ de 1,2. Em outras palavras, o município não pode dever mais que $120 \%$ de sua RCL. Elenca-se que esse estudo não inclui as obrigações existentes entre as administrações diretas 
A Desvalorização da Remuneração Docente na Disputa pelo Fundo Público Municipal

dos Estados, do Distrito Federal ou dos Municípios e seus respectivos fundos, autarquias, fundações e empresas estatais dependentes, ou entre estes, por não comporem a dívida consolidada.

A Tabela 1 traz um contexto de evolução em termos de disputa pelo fundo público, estratificando as despesas municipais por função.

Tabela 1 - Percentual de Gastos Municipais por Função da Prefeitura Municipal de Curitiba entre 2016 e abril de 2018

\begin{tabular}{|c|c|c|c|c|}
\hline Função & (\%) 2016 & (\%) 2017 & $\begin{array}{l}(\%) \text { até abril } \\
2018\end{array}$ & $\begin{array}{l}\text { Variação } 2016 \text { - } \\
2017(\%)\end{array}$ \\
\hline Legislativa & 1,67 & 1,32 & 1,25 & $-20,96$ \\
\hline Essencial à Justiça & 0,69 & 0,61 & 0,58 & $-11,59$ \\
\hline Administração & 10,49 & 7,83 & 6,1 & $-25,36$ \\
\hline Subfunção Comunicação Social & 0,05 & 0,06 & 1,49 & 20,00 \\
\hline Segurança Pública & 1,76 & 1,66 & 0,01 & $-5,68$ \\
\hline Assistência Social & 2,33 & 2,13 & 1,62 & $-8,58$ \\
\hline Previdência Social & 12,25 & 13,09 & 24,4 & 6,86 \\
\hline Saúde & 23,45 & 22,44 & 19,93 & $-4,31$ \\
\hline Trabalho & 0,07 & 0,05 & 0,03 & $-28,57$ \\
\hline Educação & 21,89 & 18,88 & 16,04 & $-13,75$ \\
\hline Cultura & 0,72 & 0,61 & 0,54 & $-15,28$ \\
\hline Direito da Cidadania & 0,01 & 0,01 & 0,02 & 0,00 \\
\hline Urbanismo & 14,99 & 13,76 & 11,58 & $-8,21$ \\
\hline Habitação & 0,11 & 0,11 & 0,2 & 0,00 \\
\hline Saneamento & 2,67 & 3,41 & 2,57 & 27,72 \\
\hline Gestão Ambiental & 1,52 & 1,56 & 0,87 & 2,63 \\
\hline Comércio e Serviços & 0,91 & 0,8 & 0,7 & $-12,09$ \\
\hline Desporto e Lazer & 0,49 & 0,48 & 0,4 & $-2,04$ \\
\hline Encargos Especiais - Dívida & 4,37 & 11,24 & 12,04 & 157,21 \\
\hline
\end{tabular}

Fonte: Elaborada pelo autor com base nos dados obtidos em: Curitiba (2018).

Entre as funções elencadas, optou-se por destacar uma subfunção da Administração: a comunicação social. A variação é 2017 e 2016 é de $20 \%$ e a tendência para 2018 é de um aumento maior.

Destacam-se aumentos com os as despesas da previdência e saneamento. Todavia, são nos encargos especiais em que os gastos têm um aumento substancial, 157,21\% em um ano, com tendência de manutenção em 2018. Nesses gastos se incluem os serviços da dívida pública interna e externa e encargos especiais. A tabela ainda evidencia que alguns investimentos sofreram com a nova ordenação de prioridades do município, particularmente a educação e a saúde.

Salvador (2012) e Brettas (2012) argumentam que os direitos sociais com reserva mínima de orçamento regulado pela Constituição costumam provocar um discurso conservador de engessamento orçamentário. Tendo em vista que para o financiamento da educação não se pode investir menos que $25 \%$ das receitas de impostos e Fundo de Participação dos Municípios, essa função costuma ser alvo de reformas pelo seu impacto na execução orçamentária. Esse cenário se complementa pela grande quantidade de cidadãos que usufruem desse direito diariamente, e, por conseguinte, emprega no serviço público uma grande quantidade de trabalhadoras e trabalhadores, e, por consequência, impactantes na execução orçamentária municipal. 
A Desvalorização da Remuneração Docente na Disputa pelo Fundo Público Municipal

A Tabela 2 busca investigar alocação do fundo público para a dívida em um contexto de cumprimento da LRF. Portanto, organizou-se os dados do Tribunal de Contas do Estado do Paraná (TCE-PR) acerca do demonstrativo da Dívida Consolidada Líquida (DCL).

Tabela 2 - Divida Consolidada e Cumprimento da Lei de Responsabilidade Fiscal em Curitiba entre 2016 e abril de 2018

\begin{tabular}{lrrr}
\hline Descrição & 2016 & 2017 & Abril de 2018 \\
\hline Dívida Consolidada & $\mathrm{R} \$ 1.721 .630 .091,97$ & $\mathrm{R} \$ 1.566 .610 .659,64$ & $\mathrm{R} \$ 1.531 .794 .878,22$ \\
Dívida contratual & $\mathrm{R} \$ 1.705 .126 .643,67$ & $\mathrm{R} \$ 1.566 .610 .659,64$ & $\mathrm{R} \$ 1.531 .794 .878,22$ \\
Disponibilidade de Caixa Bruta & $\mathrm{R} \$ 553.141 .780,68$ & $\mathrm{R} \$ 1.368 .032 .691,93$ & $\mathrm{R} \$ 1.867 .105 .318,72$ \\
Demais haveres financeiros & $\mathrm{R} \$ 40.404 .143,45$ & $\mathrm{R} \$ 0,00$ & $\mathrm{R} \$ 0,00$ \\
Restos a pagar processados & $\mathrm{R} \$ 94.253 .037,24$ & $\mathrm{R} \$ 19.039 .689,66$ & $\mathrm{R} \$ 86.559 .344,04$ \\
Disponibilidade de Caixa líquida & $\mathrm{R} \$ 499.292 .886,89$ & $\mathrm{R} \$ 1.348 .993 .002,27$ & $\mathrm{R} \$ 1.780 .545 .974,68$ \\
Dívida Consolidada Líquida (DCL) & $\mathrm{R} \$ 1.222 .337 .205,08$ & $\mathrm{R} \$ 217.617 .657,37$ & $\mathrm{R} \$ 0,00$ \\
Receita Corrente Líquida (RCL) & $\mathrm{R} \$ 6.431 .176 .668,39$ & $\mathrm{R} \$ 6.665 .454 .954,03$ & $\mathrm{R} \$ 6.832 .548 .654,86$ \\
\% DA DCL/RCL & 19,01 & 3,26 & 0 \\
Limite definido por resolução do & $\mathrm{R} \$ 7.717 .412 .002,07$ & $\mathrm{R} \$ 7.998 .545 .944,84$ & $\mathrm{R} \$ 8.199 .058 .385,83$ \\
Senado Federal - < R $>$ & & &
\end{tabular}

Fonte: Elaborada pelo autor com base nos dados obtidos em: Paraná (2018).

O município de Curitiba não tem dívida mobiliária, ou seja, não emite títulos públicos em troca de injeção de capital para o orçamento. Houve uma diminuição da dívida consolidada bruta do município, essencialmente com base nas dívidas contratuais. O aumento da receita corrente líquida (RCL) também é substancial para um discurso de crise, pois, de 2016 para 2017 o aumento foi de $3,64 \%$ e, de abril de 2018 e os 11 meses anteriores, $2,5 \%$. Chama atenção a disponibilidade de caixa líquida, proveniente da disponibilidade bruta subtraída dos restos a pagar processados. Essa disponibilidade abate da dívida consolidada bruta, gerando a dívida consolidada líquida (DCL), que, de 1,2 bilhão de reais ao final de 2016, chega à nulidade em abril de 2018.

Entretanto, pelo limite definido pela lei de responsabilidade fiscal, em 2016 o município ainda mantinha bom controle sobre a dívida pública, na proporção de DCL de $19 \%$ do total da $\mathrm{RCL}$, quando, pela referida legislação, o limite máximo municipal é de $120 \%$.

Esse cenário auxilia no entendimento de que, mesmo com o controle da dívida pública pelo município, a gestão optou por alocar recurso para garantir disponibilidade de caixa e, consequentemente, diminuir a razão $\mathrm{DCL} / \mathrm{RCL}$, penalizando os servidores públicos com arrochos salariais e a consequente desvalorização de suas remunerações, sem motivo emergencial de controle fiscal. O panorama é complementado com a Tabela 3, a seguir, que apresenta o panorama de despesa com pessoal no município pela ótica da LRF.

Tabela 3 - Despesa com Servidores Municipais de Curitiba entre 2016 e 2018 na Análise da LRF

\begin{tabular}{lrrr}
\hline Descrição & 2016 & 2017 & Até abril de 2018 \\
\hline Despesa bruta com pessoal & $\mathrm{R} \$ 4.005 .492 .796,35$ & $\mathrm{R} \$ 3.909 .789 .177,71$ & $\mathrm{R} \$ 3.963 .540 .097,52$ \\
Ativos & $\mathrm{R} \$ 2.983 .174 .266,33$ & $\mathrm{R} \$ 2.721 .929 .474,50$ & $\mathrm{R} \$ 2.732 .477 .107,21$ \\
Inativos e pensionistas & $\mathrm{R} \$ 801.346 .649,05$ & $\mathrm{R} \$ 961.116 .167,17$ & $\mathrm{R} \$ 1.001 .236 .376,18$ \\
Terceirizados & $\mathrm{R} \$ 220.971 .880,97$ & $\mathrm{R} \$ 226.743 .536,04$ & $\mathrm{R} \$ 229.826 .614,13$ \\
Despesa líquida com pessoal & $\mathrm{R} \$ 2.970 .947 .500,51$ & $\mathrm{R} \$ 2.742 .567 .050,49$ & $\mathrm{R} \$ 2.755 .755 .327,50$ \\
$\begin{array}{l}\text { Restos a pagar não } \\
\text { processados }\end{array}$ & $\mathrm{R} \$ 3.338 .190,70$ & $\mathrm{R} \$ 5.370 .870,44$ & $\mathrm{R} \$ 5.370 .870,44$ \\
$\begin{array}{l}\text { Despesa total com pessoal } \\
\text { (\%) DLP/RCL }\end{array}$ & $\mathrm{R} \$ 2.974 .285 .691,21$ & $\mathrm{R} \$ 2.747 .937 .920,93$ & $\mathrm{R} \$ 2.761 .126 .197,94$ \\
Limite máximo & 46,25 & 41,23 & 40,42 \\
\hline
\end{tabular}

Fonte: Elaborada pelo autor com base nos dados obtidos em: Paraná (2018). 
A Desvalorização da Remuneração Docente na Disputa pelo Fundo Público Municipal

O cenário apresentado evidencia algumas questões. O aumento de despesas com inativos é, em montante financeiro, similar ao decréscimo de despesas com servidores. Os quase $R \$ 200.000 .000,00$ foram compensados no pagamento de inativos. A despesa líquida com pessoal foi reduzida e os gastos com terceirizados ampliada.

Entretanto, o que chama atenção é o cumprimento da LRF. Em 2016, a razão entre a despesa líquida com pessoal e a receita corrente líquida estava em 46,25\%, 7,75\% distante do limite máximo permitido pela referida legislação, o que corresponde a um montante equivalente a quase 500 milhões de reais. Entretanto, as ações de desvalorização dos servidores municipais encolheram essa razão para 40,42\%, aumentando esse montante de margem para mais de 900 milhões de reais.

No que tange à remuneração docente, a ausência de dados desagregados no TCE PR implicou na consulta ao Siope do montante de todos os profissionais da educação. Nesse sentido, algumas informações dialogam com o panorama analisado acima.

Tabela 4 - Montante investido em remuneração dos profissionais da educação entre 2016 e 2017

\begin{tabular}{lrr}
\hline Despesas em educação & 2016 & 2017 \\
\hline Vencimentos e vantagens fixas de docentes & $\mathrm{R} \$$ 864.247.412,93 & $\mathrm{R} \$ 831.897 .043,60$ \\
Serviços de terceiros & $\mathrm{R} \$ 136.870 .368,86$ & $\mathrm{R} \$ 162.106 .555,79$ \\
\hline
\end{tabular}

Fonte: Elaborada pelo autor com base nos dados obtidos em: Brasil (2018a).

De acordo com a Tabela 4, o montante de vencimentos e vantagens fixas diminuiu entre os dados consolidados de execução orçamentária dos dois anos, assim como aumentou as despesas com serviços de terceiros, auxiliando no entendimento de um contexto local de disputa e as decisões políticas de uma concepção política de alocação do fundo público. Em 2017, o Índice Nacional de Preço ao Consumidor Amplo, calculado pelo Instituto Brasileiro de Geografia e Estatística para o acumulado do ano de 2016 foi de 6,28\%. O mesmo cálculo para o acumulado de 2017 foi de 2,94\%. Em um breve exercício (Tabela 5), com base no montante de despesas em remuneração docente em 2016, a reposição salarial em 2017 e em 2018 com base no montante estimado do ano anterior teriam um impacto pouco relevante para um município do porte de Curitiba.

Tabela 5 - Exercício de Estimativa de Aumento do Montante da Remuneração Docente no Município de Curitiba com Base no IPCA (2017-2018)

\begin{tabular}{lrr}
\hline Descrição & 2017 & 2018 \\
\hline Vencimentos reajustados pelo IPCA & $\mathrm{R} \$ 918.608 .575,20$ & $\mathrm{R} \$ 945.615 .667,31$ \\
\hline IPCA & $6,28 \%$ & $2,94 \%$ \\
\hline
\end{tabular}

Fonte: Elaborada pelo autor com base nos dados obtidos em: Brasil (2018a) e IBGE (2018).

O cenário indica um impacto no biênio 2016-2018 de pouco mais de 90 milhões. Tratase, sobretudo, de um posicionamento político acerca da valorização da remuneração dos profissionais da educação, e, consequentemente, dos docentes, que carece de construção de legitimidade para reaver sua condição de dignidade.

Ademais, a análise evidencia um contexto em que a financeirização da riqueza de poucos e os contratos terceirizados parecem ser a prioridade na ordenação de valores da atual gestão municipal, desvalorizando as remunerações dos servidores e ampliando a crise econômica da população trabalhadora do município. 
A Desvalorização da Remuneração Docente na Disputa pelo Fundo Público Municipal

\section{Considerações Finais}

A disputa política pelo fundo público é um fenômeno da modernidade e perceptível no plano municipal. No caso de Curitiba, em pouco mais de um ano de uma gestão que segue um modelo gerencial e neoliberal, percebeu-se a transição da educação para uma subprioridade, materializada na redução do seu financiamento.

Consequentemente, a remuneração dos servidores públicos municipais, incluindo os professores públicos, vem sofrendo com as políticas de austeridade implantadas por este grupo político, que, em detrimento do investimento nas condições de vida da população pela via das políticas públicas e de seus servidores, da progressão em planos de carreira e ausência de diálogo na reposição salarial, ao menos pelo índice inflacionário oficial do país, optou pela alocação de recursos em outros encargos como amortização de juros da dívida pública e reserva de disponibilidade de caixa para zerar a dívida consolidada líquida.

No que diz respeito à LRF, desde 2016 é perceptível que o município tinha controle sobre a dívida e distanciamento dos limites máximos que a referida lei impõe aos municípios, seja no que diz respeito à dívida pública ou ao investimento financeiro em remuneração de pessoal, cenário que auxilia a legitimar que, no contexto atual, trata-se, sobretudo, de decisões políticas na alocação do recurso de não valorização do servidor público pela via da remuneração.

Ademais, o histórico de profissionalização docente e luta por valorização, em um contexto nacional onde as políticas do Governo Federal, como a Emenda Constitucional n. 95 (BRASIL, 2016) e a própria LRF legitimam ações de austeridade no plano municipal pesando no financiamento da educação, evidencia tempos difíceis e de tensionamento do Estado para que efeitos negativos nas conquistas da classe sejam reduzidos por posicionamentos políticos que não ordenam a remuneração docente como prioridade de investimento.

\section{Referências}

ANÍBAL, Felippe. Rafael Greca diz que vai manter urgência do ajuste fiscal "a qualquer preço". Tribuna do Paraná, Curitiba, 21 jun. 2017. Disponível em: <https://www.tribunapr.com.br/ noticias/curitiba-regiao/rafael-greca-diz-que-vai-manter-urgencia-do-ajuste-fiscal-a-qualquerpreco/>. Acesso em: 13 jul. 2017.

BARBOSA, Maria Lígia Oliveira. A sociologia das profissões: em torno da legitimidade de um objeto. Anpocs, São Paulo, v. 36, p. 3-30, 1993.

BRASIL. Lei $n^{\circ}$ 5.692, de 11 de agosto de 1971. Fixa Diretrizes e Bases para o ensino de $1^{\circ}$ e $2^{\circ}$ graus, e dá outras providências. Diário Oficial da União, Brasília, 12 ago. 1971.

BRASIL. Constituição da República Federativa do Brasil de 1988. Constituição da República Federativa do Brasil. Diário Oficial da União, Brasília, 05 out. 1988.

BRASIL. Lei Complementar n. 101, de 04 de maio de 2000. Estabelece normas de finanças públicas voltadas para a responsabilidade na gestão fiscal e dá outras providências. 2000. Diário Oficial [da] República Federativa do Brasil, Brasília, DF, 05 mai. 2000. Disponível em: <http://www.planalto.gov.br/ccivil_03/leis/LCP/Lcp101.htmErro! A referência de hiperlink não é válida. 
A Desvalorização da Remuneração Docente na Disputa pelo Fundo Público Municipal

BRASIL. Senado Federal. Resolução n. 40 de 20 de dezembro de 2001. Dispõe sobre os limites globais para o montante da dívida pública consolidada e da dívida pública mobiliária dos Estados, do Distrito Federal e dos Municípios, em atendimento ao disposto no art. 52, VI e IX, da Constituição Federal. Diário Oficial [da] República Federativa do Brasil, Brasília, DF, 10 abr. 2002. Disponível em: <http://www2.camara.leg.br/legin/fed/ressen/2001/ resolucao-40-20-dezembro-2001-429320-normaatualizada-pl.html>. Acesso em: 14 jul. 2018.

BRASIL. Emenda Constitucional n. 95, de 15 de dezembro de 2016. Altera o Ato das Disposições Constitucionais Transitórias, para instituir o Novo Regime Fiscal, e dá outras providências. 2016. Diário Oficial [da] República Federativa do Brasil, Brasília, DF, 15 dez. 2016. Disponível em: <http://www.planalto.gov.br/ccivil_03/constituicao/emendas/emc/ emc95.htmErro! A referência de hiperlink não é válida.

BRASIL. Lei n. 13.415, de 16 de fevereiro de 2017. Altera as Leis nos 9.394, de 20 de dezembro de 1996, que estabelece as diretrizes e bases da educação nacional, e 11.494, de 20 de junho 2007, que regulamenta o Fundo de Manutenção e Desenvolvimento da Educação Básica e de Valorização dos Profissionais da Educação, a Consolidação das Leis do Trabalho - CLT, aprovada pelo Decreto-Lei no 5.452, de 1 o de maio de 1943, e o Decreto-Lei no 236, de 28 de fevereiro de 1967; revoga a Lei no 11.161, de 5 de agosto de 2005; e institui a Política de Fomento à Implementação de Escolas de Ensino Médio em Tempo Integral. 2017. Diário Oficial [da] República Federativa do Brasil, Brasília, DF, 17 fev. 2017. Disponível em: <http://www.planalto.gov.br/ccivil_03/_ato2015-2018/2017/lei//13415.htmErro! A referência de hiperlink não é válida.

BRASIL. Ministério da Educação. Sistema de Informações Sobre Orçamento Público em Educação (SIOPE). Brasília: FNDE, 2018a. Disponível em: <http://www.fnde.gov.br/fndesistemas/sistema-siope-apresentacao/siope-apresentacao>. Acesso em: 14 jul. 2018.

BRASIL. Ministério da Fazenda. Indicadores fiscais e de endividamento de estados e municípios. Brasília: Secretaria do Tesouro Nacional, 2018b. Disponível em: <http://www.tesouro.fazenda.gov.br/indicadores-fiscais-e-de-endividamento>. Acesso em 14 jul. 2018.

BRETTAS, Tatiana. Dívida Pública: uma varinha de condão sobre os recursos do fundo público. In: SALVADOR, Evilasio et al. (Org.). Financeirização, Fundo Público e Política Social. 1 ed. São Paulo: Cortez, 2012. p. 93-120.

CURITIBA. Prefeitura Municipal. Lei $n^{\circ} 10.090$ de 28 de junho de 2001. Institui o Plano de Carreira do Magistério Público Municipal, alterando as leis $n^{\circ}$ 8580/94, 6761/85 e 8579/94. Diário Oficial do Município de Curitiba, Curitiba, PR, 28 jun. 2001.

CURITIBA. Prefeitura Municipal. Lei $n^{\circ} 14.544$ de 11 de novembro de 2014. Institui o Plano de Carreira do Profissional do Magistério de Curitiba. Diário Oficial do Município de Curitiba, Curitiba, PR, 11 nov. 2014.

CURITIBA. Prefeitura Municipal. Lei $n^{\circ} 387$ de 17 de abril de 2015. Regulamenta os artigos 17 a 20, da Lei Municipal $n^{\circ} 14.544$, de 11 de novembro de 2014 , e dá outras providências. Diário Oficial do Município de Curitiba, Curitiba, PR, 17 abr. 2015. 
A Desvalorização da Remuneração Docente na Disputa pelo Fundo Público Municipal

CURITIBA. Prefeitura Municipal. Lei $n^{\circ} 15.043$ de 28 de junho de 2017. Altera o art. $1^{\circ}$ da Lei Municipal $n^{\circ} 8.680 / 1995$; suspende os planos de carreira previstos nas Leis Municipais $10.190 / 2001,11.000 / 2004,11.001 / 2004,12.083 / 2006,13.769 / 2011,13.770 / 2011$, 14.507/2014, 14.522/2014, 14.544/2014, 14.580/2014; altera o art. $1^{\circ}$ da Lei Municipal $n^{\circ}$ 6.449/1983, altera os arts. 91 e 165 a 170 da Lei Municipal $n^{\circ} 1.656 / 1958$; acrescenta o $\S 3^{\circ}$ ao art. $1^{\circ}$ da Lei Municipal $n^{\circ} 13.142 / 2009$; altera o art. $2^{\circ}$ da Lei Municipal $n^{\circ} 8.704 / 1995$; altera o $\S 3^{\circ}$ do art. $6^{\circ}$ da Lei Municipal $n^{\circ} 8.660 / 1995$; altera o art. $1^{\circ}$ da Lei Municipal $n^{\circ}$ 13.948/2012; revoga os arts. 53 e 54 da Lei Municipal $n^{\circ} 6.761 / 1985$; revoga o art. $2^{\circ}$ da Lei Municipal $n^{\circ} 8.680 / 1995$; revoga os arts. $1^{\circ}$ a $4^{\circ}$ da Lei Municipal $n^{\circ} 8.995 / 1996$ e dá outras providências. Diário Oficial do Município de Curitiba, Curitiba, PR, 28 jun. 2017.

CURITIBA. Portal da Transparência da Prefeitura Municipal de Curitiba. Curitiba, 2018. Disponível em: <http://www.portaldatransparencia.curitiba.pr.gov.br>. Acesso em: $30 \mathrm{dez}$. 2017.

FERRAZ, Marcos Alexandre. Estado, política e sociabilidade. In: GOUVEIA, Andrea Barbosa; SOUZA, Angelo Ricardo de; TAVARES, Tais Moura. Políticas Educacionais: conceitos e debates. Curitiba: Appris, 2011. p. 25-51.

FERREIRA JÚNIOR, Amarilio; BITTAR, Marisa. A ditadura militar e a proletarização dos professores. Educação \& Sociedade, Campinas, v. 27, n. 97, 2006.

GROCHOSKA, Marcia Andreia. Políticas educacionais e a valorização do professor: carreira e qualidade de vida dos professores de educação básica do município de São José dos Pinhais/PR. 2015. 269 f. Tese (Doutorado em Educação) - Programa de Pós-Graduação em Educação, Setor de Educação, Universidade Federal do Paraná, Curitiba, 2015.

INSTITUTO BRASILEIRO DE GEOGRAFIA E ESTATÍSTICA (IBGE). Remuneração Docente no Município de Curitiba. Brasília: Ministério do Planejamento, 2018. Disponível em: <www.ibge.gov.br>. Acesso em: 13 jul. 2017.

OLIVEIRA, Dalila Andrade. Os trabalhadores docentes e a construção política da profissão docente no Brasil. Educar em Revista, Curitiba, v. 1, n. 1, p. 17-36, 2010.

OLIVEIRA, Francisco de. Surgimento do antivalor. In: OLIVEIRA, Francisco de (Org.). Os direitos do antivalor: a economia política da hegemonia imperfeita. Petrópolis: Vozes, 1998. p. 19-48.

PARANÁ. Tribunal de Contas. Relatórios da Lei de Responsabilidade Fiscal: Curitiba, 2018. Disponível em: <https://servicos.tce.pr.gov.br/TCEPR/Municipal/SIMAM/Paginas/ Rel_LRF.aspx?relTipo=1>. Acesso em 13 jul. 2017.

POCHMANN, Marcio. Proteção social na periferia do capitalismo: considerações sobre o Brasil. São Paulo em Perspectiva, São Paulo, v. 18, n. 2, p. 3-16, 2004.

POGGI, Gianfranco. A evolução do Estado Moderno: uma introdução sociológica. Rio de Janeiro: Zahar, 1981.

POULANTZAS, Nicos. O Estado, o poder, o socialismo. 2. ed. Rio de Janeiro: Graal, 1985. 
A Desvalorização da Remuneração Docente na Disputa pelo Fundo Público Municipal

QUINTILIANO, Leonardo David. Autonomia federativa: delimitação no direito constitucional brasileiro. 2012. 321 f. Tese (Doutorado em Direito) - Faculdade de Direito do Largo São Francisco, Universidade de São Paulo, São Paulo, 2012.

SALVADOR, Evilasio. Fundo público e políticas sociais na crise do capitalismo. Serviço Social \& Sociedade, São Paulo, n. 104, p. 605-631, out./dez. 2010.

SALVADOR, Evilasio. Fundo público e financiamento das políticas sociais no Brasil. Serviço Social em Revista, Londrina, v. 14, n. 2, p. 504-522, jan./jun. 2012.

SOUZA, Donaldo Bello de; FARIA, Lia Ciomar Macedo de. Reforma do Estado, descentralização e municipalização do ensino no Brasil: a gestão política dos sistemas públicos de ensino pós-LDB 9.394/96. Ensaio: Avaliação e Políticas Públicas em Educação, Rio de Janeiro, v. 12, n. 45, p. 925-944, out./dez. 2004.

VICENTINI, Paula Perin; LUGLI, Rosário Genta. História da profissão docente no Brasil. São Paulo: Cortês, 2009.

Marcus Quintanilha da Silva é professor substituto da Universidade Federal do Paraná. Professor do Magistério Superior pela Faculdade São Braz. Mestre em Educação Universidade Federal do Paraná. Doutorando em Educação - Universidade Federal do Paraná.

ORCID: http://orcid.org/0000-0002-8305-0024

E-mail: marcusquintanlha@hotmail.com 


\section{Editores do volume 10}

Márcia Aparecida Jacomini - Universidade Federal de São Paulo, Brasil

José Marcelino de Rezende Pinto - Universidade de São Paulo, Brasil

\section{Comitê Editorial}

Nalú Farenzena - Universidade Federal do Rio Grande do Sul, Brasil

Juca Gil - Universidade Federal do Rio Grande do Sul, Brasil

Theresa Adrião - Universidade Estadual de Campinas, Brasil

Ângelo Ricardo de Souza - Universidade Federal do Paraná, Brasil

\section{Conselho Editorial}

\section{Alejandro Morduchowicz}

Universidad Pedagógica, Provincia de Buenos Aires, Argentina

Andréa Barbosa Gouveia

Universidade Federal do Paraná, Brasil

Fernanda Saforcada

Universidade de Buenos Aires, Argentina

Jacques Velloso

Universidade de Brasília, Brasil

João Monlevade

Senado Federal, Brasil

Jorge Abrahão de Castro

Instituto de Pesquisa Econômica Aplicada / IPEA, Brasil

Lisete Regina Gomes Arelaro

Universidade de São Paulo, Brasil

Luis Carlos Sales

Universidade Federal do Piauí, Brasil

Luiz de Sousa Junior

Universidade Federal da Paraíba, Brasil

Luiz Fernandes Dourado

Universidade Federal de Goiás, Brasil

Magna França

Universidade Federal do Rio Grande do Norte, Brasil

Marcos Edgar Bassi

Universidade Federal de Santa Catarina, Brasil

Maria Angélica Pedra Minhoto

Universidade Federal de São Paulo, Brasil

Maria Beatriz Luce

Universidade Federal do Rio Grande do Sul, Brasil

Maria Dilnéia Espíndola Fernandes

Universidade Federal de Mato Grosso do Sul, Brasil

Nelson Cardoso do Amaral

Universidade Federal de Goiás, Brasil

Nicholas Davies

Universidade Federal Fluminense, Brasil

Robert E. Verhine

Universidade Federal da Bahia, Brasil

Romualdo Portela de Oliveira Universidade de São Paulo, Brasil

Rosana Gemaque Rolim

Universidade Federal do Pará, Brasil

Rubens Barbosa de Camargo

Universidade de São Paulo, Brasil

Theresa Adrião

Universidade Estadual de Campinas, Brasil

Tristan McCowan

University of London, Reino Unido

Vera Jacob

Universidade Federal do Pará, Brasil

Vera Peroni

Universidade Federal do Rio Grande do Sul, Brasil

Vitor Henrique Paro

Universidade de São Paulo, Brasil

\section{Equipe editorial}

Apoio ao Comitê Editorial: Caio Cabral da Silva

Diagramação, Revisão de português e normalização: Edson Leonel de Oliveira

Revisão de inglês: Ananyr Porto Fajardo

Fineduca - Revista de Financiamento da Educação

Associação Nacional de Pesquisa em

Financiamento da Educação

e-mail: revista.fineduca@gmail.com | site: http://seer.ufrgs.br/fineduca 